\title{
Classification of the underwater diving equipment
}

Ryszard Kłos,

Polish Naval Academy

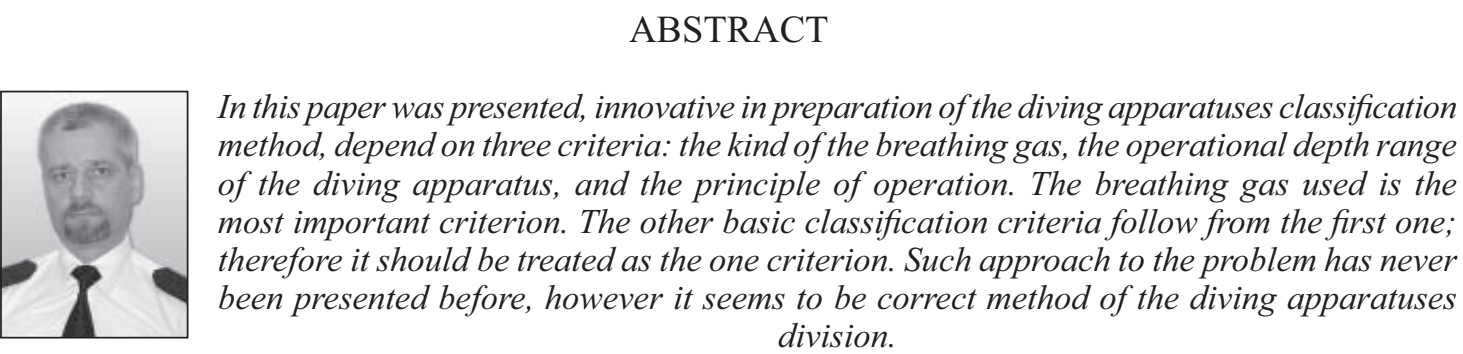

Keywords: diving apparatus, classification, underwater diving equipment

\section{INTRODUCTION - CHARACTERISTICS OF THE DIVING EQUIPMENT}

Traditionally the diving equipment can be divided into the heavy (classic) and light-weight equipment. [2, 3, 6, 7, 8, 9, $10,11,12]$.Classification of the diving equipment according to this criterion is the diving technique based.

The similar to August Siebe's construction, that has been patented in 1836, can be recognised as the heavy diving equipment. The diving equipment has been still developed and improved. However, simultaneously to the new types

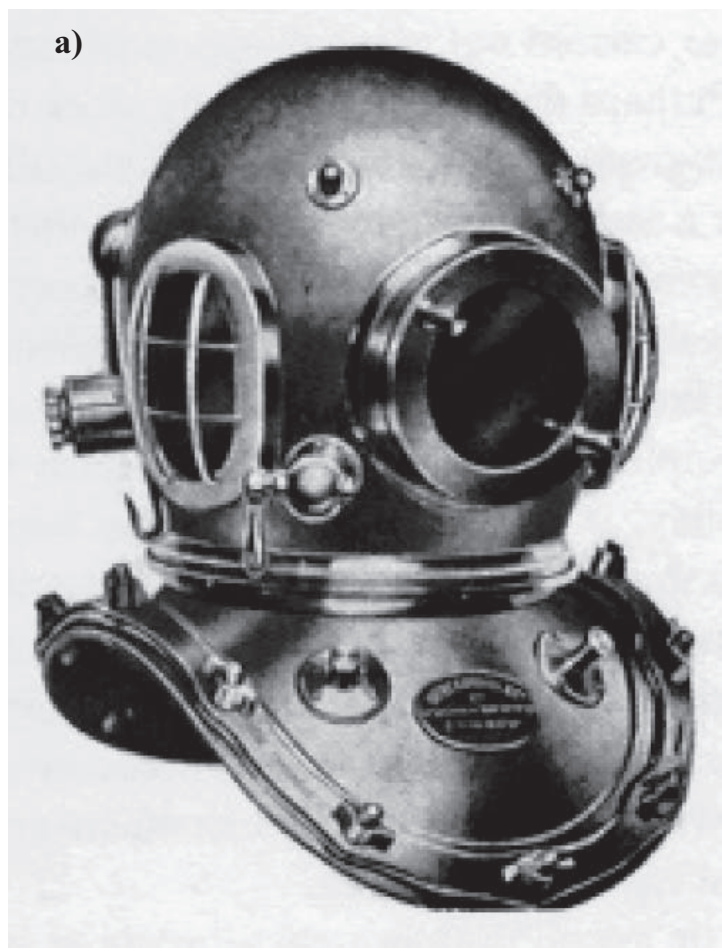

of the diving equipment the traditional Siebe's constructions are being used in actual diving operations. For these reasons sometimes it seems that the Siebe's constructions were not improved (Photo 1). Of course, this diving equipment evolved towards the helmet systems equipped with the diving regulators, however there are also the improved diving equipment with the free flow of the breathing gas. The improved diving systems DM 200/2 (Photo 2) and AH-3 are presented below (Photo 3).

The features of the heavy diving equipment are presented in Table 1. At assumption that classification criteria, presented

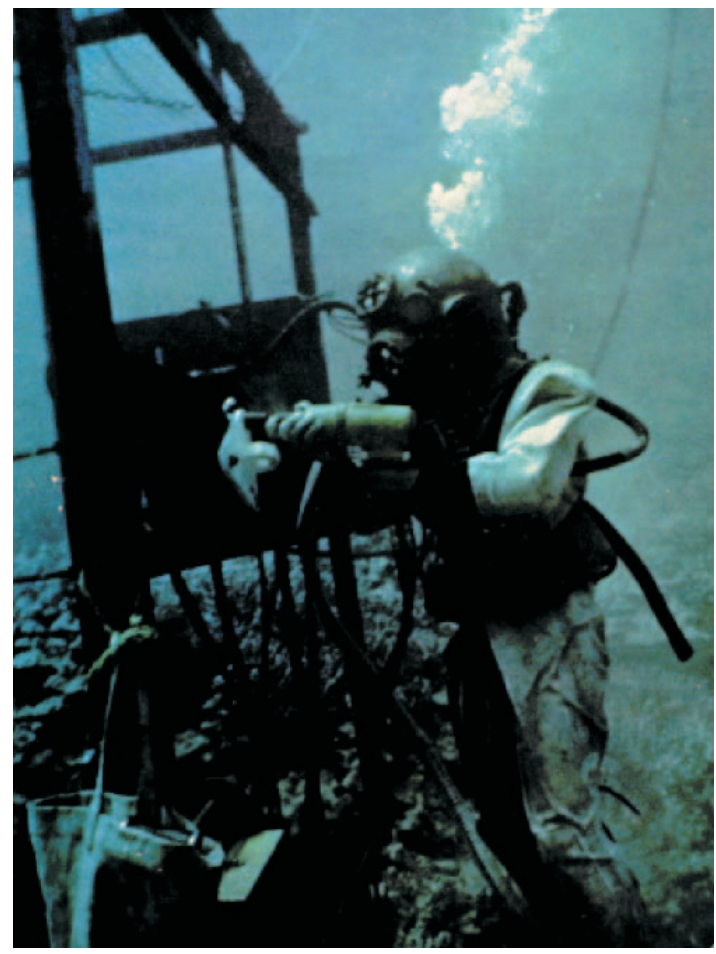

Photo 1a. The present diving helmet Siebe-Gorman (an advertising materials) 


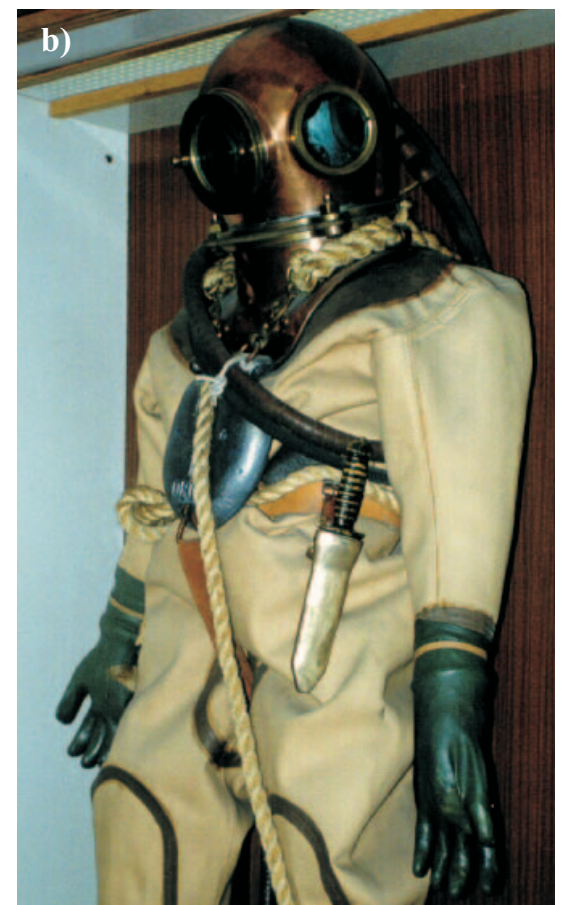

Photo $1 \mathrm{~b}$. The diving equipment with helmet UWS-50m (the own photography)

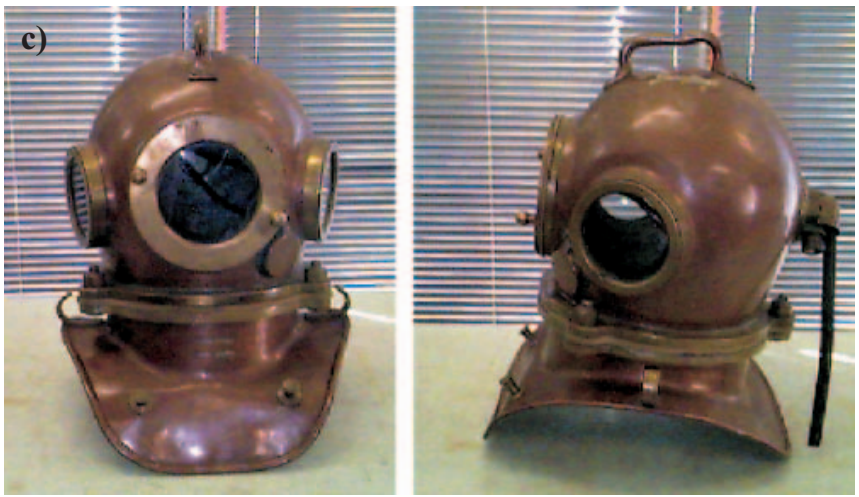

Photo 1c. The diving helmet UWS-50m (the own photography)

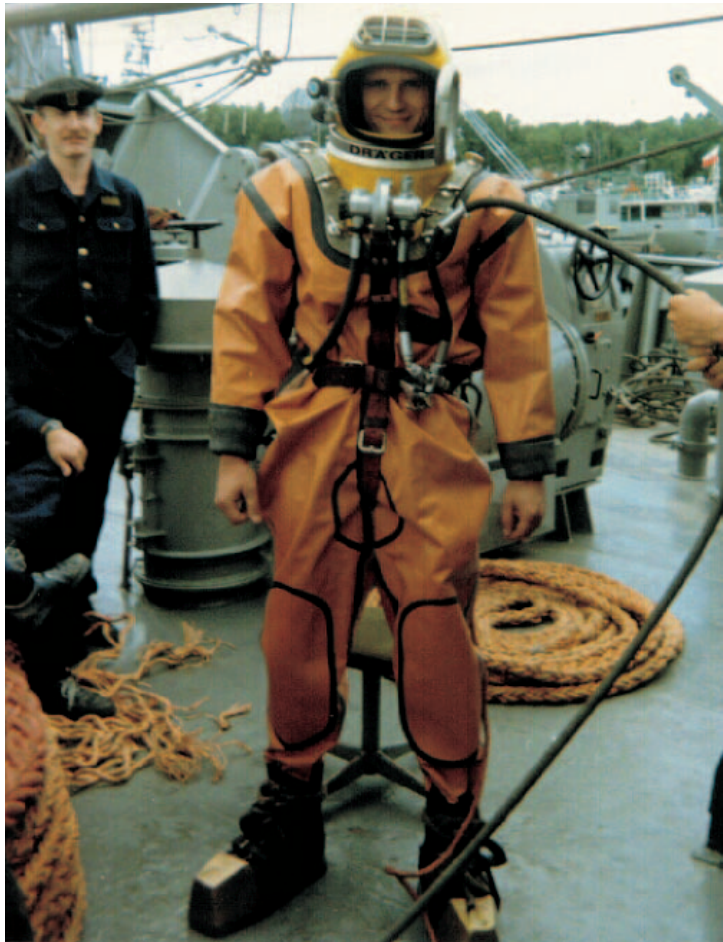

Photo 2. The diver in the diving equipment type DM 200/2 (the own photography)

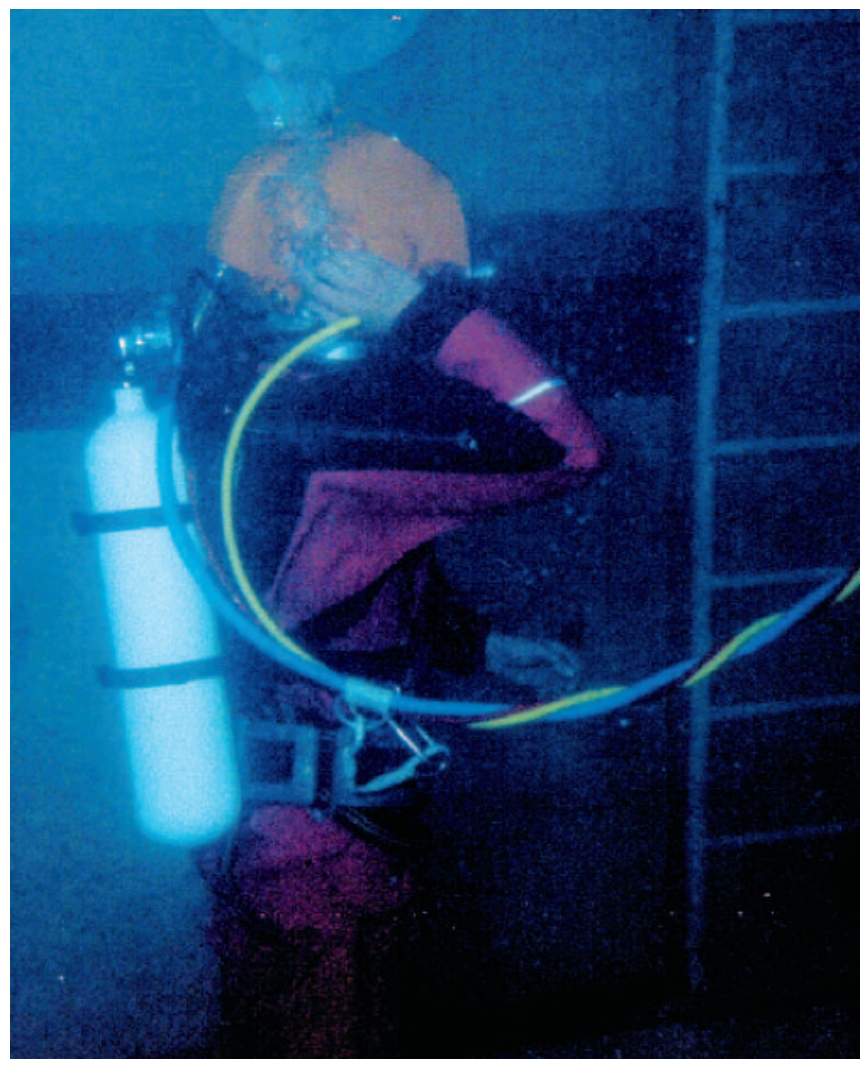

Photo 3. The diver in the diving equipment type AH-3 (the own photography)

in Table 1, distinguishing the heavy diving equipment are sufficient it should be recognised that the Henry Fleuss's oxygen diving apparatus (1879) was the independent version of the heavy diving equipment as dive consisted in displacement on the bottom of the especially loaded diver (Photo 4). Change in diving methods has led to further development of the oxygen apparatuses and their transformation into light diving equipment.
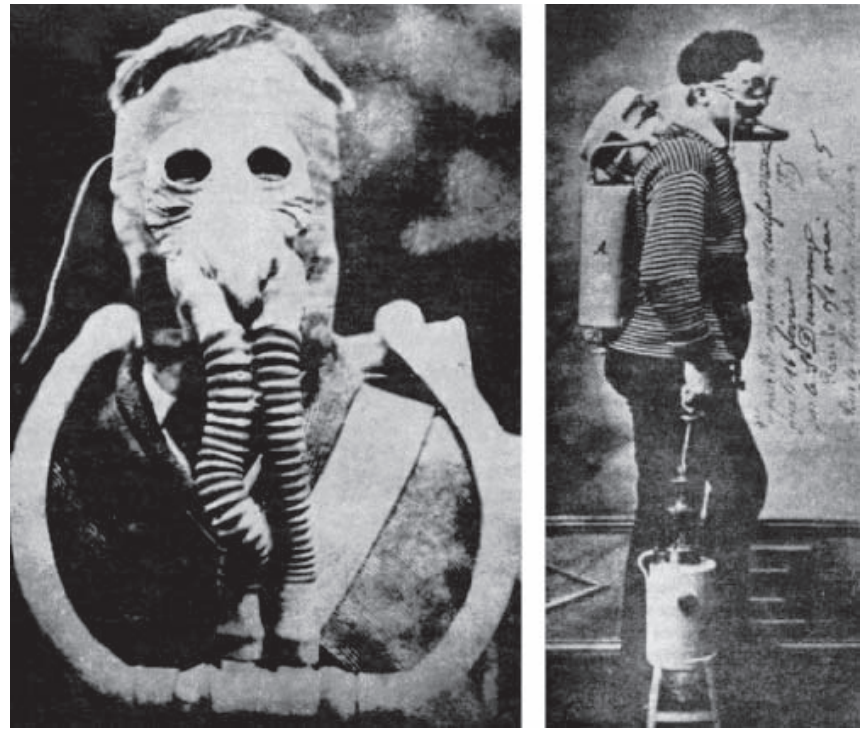

Photo 4. Henry Fleuss apparatus [4]

It is generally considered that commander Jaques Ive Cousteau is inventor of the diving apparatus used for free diving (air open-circuit self-contained underwater diving apparatus SCUBA) called Aqua-Lung (1940) - Photo 5. It is well known that the prototype such apparatus has been designed earlier. In 1860 Benoit Rouquayrol and August Denayroze have constructed similar apparatus 
(Photo 6). However, Coustau's gear has caused real landmark and has led to development of free diving. $[11,8]$.

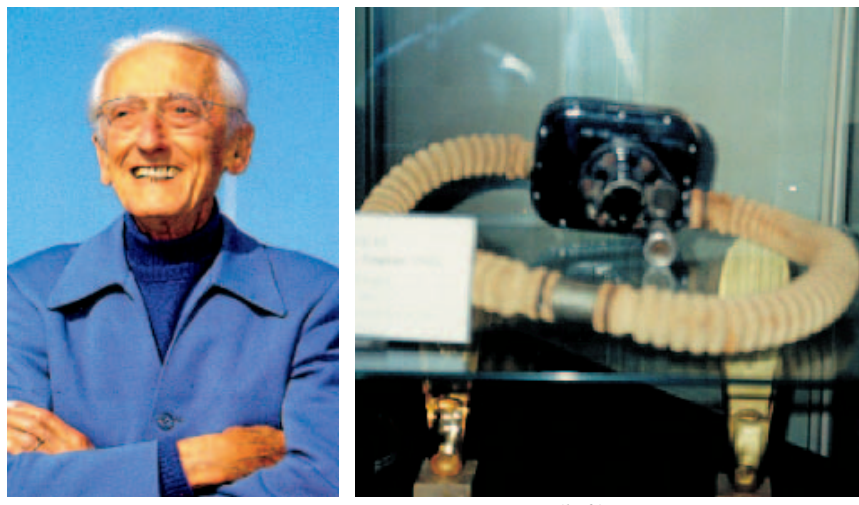

Photo 5. Jaques Ive Cousteau (left) [5].

Cousteau's diving reulator (right) (the own photography, courtesy La Spirotechnique I.C. Nicea)

Table 1. Characteristics of the heavy-weight diving equipment

The heavy-weight (classic) diving equipment

During normal work the equipped diver has high negative buoyancy. It is possible to change buoyancy, however it is only used to change the diver's work plane or while descending (ascending).

\begin{tabular}{|c|c|}
\hline Disadvantages: & $\begin{array}{c}\text {-The diver can perform work only at the } \\
\text { fixed plane such as the trap, the diving } \\
\text { platform, the bottom, decks of the } \\
\text { sunken vessel etc. } \\
\text {-The diver's mobility is limited. Moving } \\
\text { of the diver according to the work } \\
\text { planes needs to employ a large force. }\end{array}$ \\
\hline Advantages: & $\begin{array}{c}\text {-The diver's position is stabile. It gives } \\
\text { the possibility to perform the heavy } \\
\text { work without large effort to keep the } \\
\text { diver's position. }\end{array}$ \\
\hline
\end{tabular}

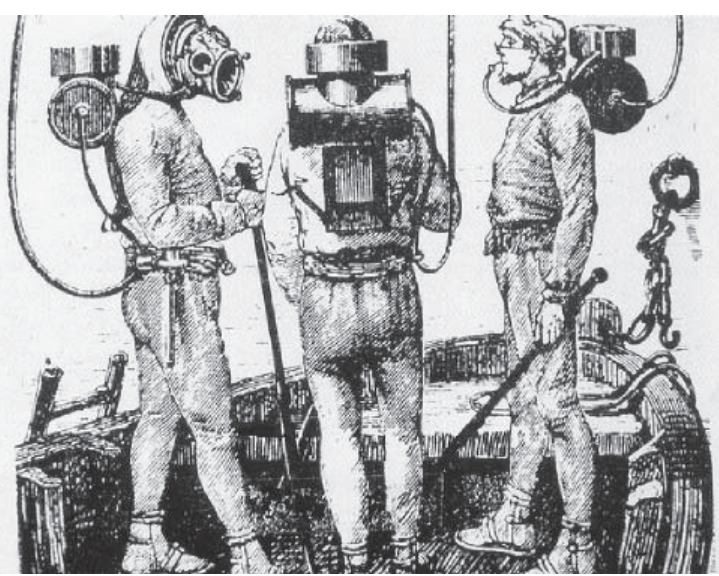

Photo. 6. Rouquayrol's apparatus [1]

Paul Bert's physiological research (Photo 7) and Elihu Thomson's theoretical works have contributed to the first experimental mixed-gas diving performed in 1924. In 1940 experiments resulted in development of the independent oxygen-nitrogen (nitrox) diving apparatus (Photo 8) proposed by Lambertsen.
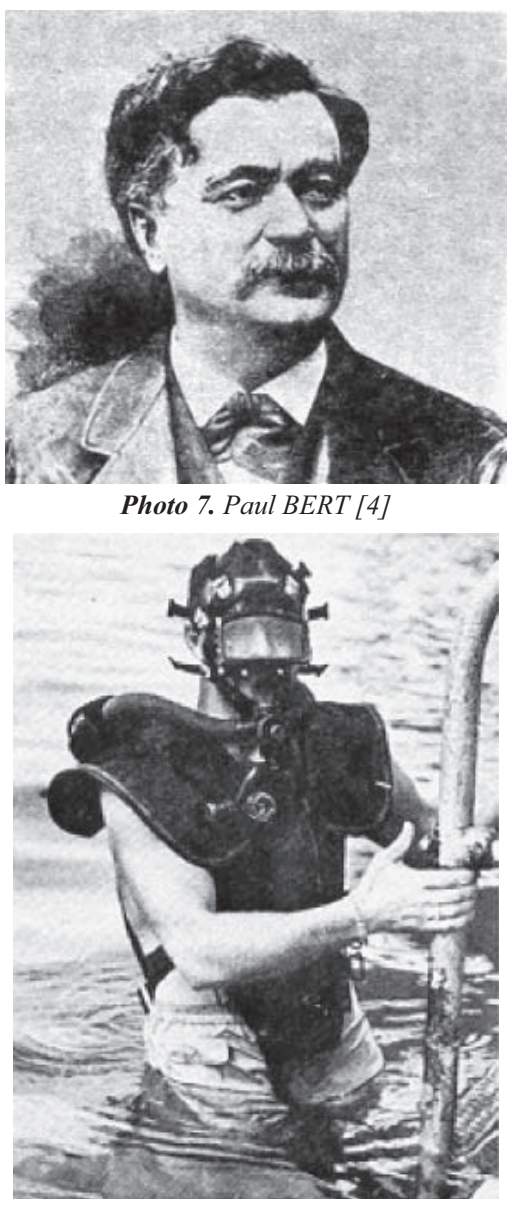

Photo 8. Lambertsen diving apparatus [11]

However, the first diving apparatus type DM 40 (Photo 9) was elaborated and manufactured by Dräger in 1915. However, many historians accept that Lambertsen's gear [11] has begun real development of the diving apparatuses. Despite of the breathing gas used, the characteristic features of the diving apparatuses are as follows (Table 2).
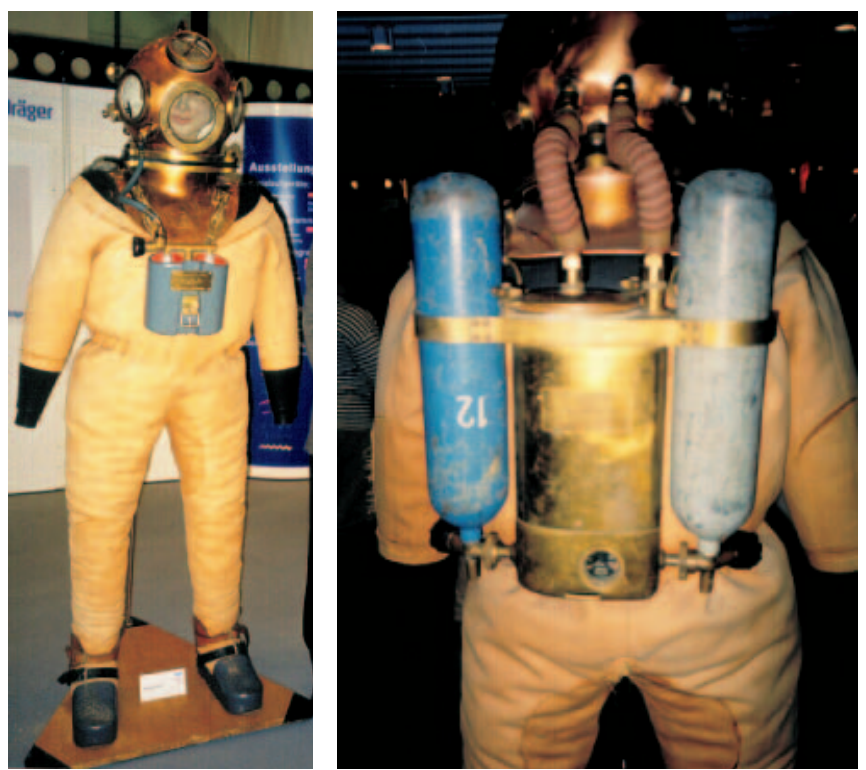

Photo 9. The diving apparatus DM 40 manufactured by Dräger 1915 (the own photography, courtesy Dräger AG Lübeck)

At present, the differences between the heavy and lightweight diving equipment are covered up as dependently upon the additional equipment chosen, the basic equipment can function as the classic or light-weight diving equipment. 
Table 2. The features of the light-weight diving equipment

The light-weight diving equipment

During normal work the equipped diver has neutral buoyancy that can be adjusted within the certain range.

\begin{tabular}{|l|c|}
\hline Disadvantages: & $\begin{array}{c}\text { The diver under water is almost } \\
\text { weightless. Even if the diver is } \\
\text { supported under water by the } \\
\text { immovable elements, weightless } \\
\text { makes the diver's work (drilling the } \\
\text { holes, surface cleaning, shooting pegs, } \\
\text { welding etc.) difficult. }\end{array}$ \\
\hline Advantages: & $\begin{array}{c}\text { Compared to heavy-weight diving } \\
\text { equipment, the light-weight one } \\
\text { enables relatively long distance diving } \\
\text { without the significant effort and free } \\
\text { displacement in all directions at depth } \\
\text { or reminding at the given place at the } \\
\text { depth. This feature enables to make } \\
\text { underwater inspection of the technical } \\
\text { state of the large underwater objects, } \\
\text { sweeping at the depth etc. }\end{array}$ \\
\hline
\end{tabular}

\section{METHODS}

Generally (here) the diving equipment is defined as follows: it is the technical equipment that enables the man safety descent, staying at the depth and ascent. There are some tendencies to extend the above definition by normobaric dives (see further). In the definition accepted it is essential that the diving equipment enable the man to perform the direct work at the depth. As it follows from above the water environment exerts the pressure on the diver's equipment that is directly transferred on the man.

This feature distinguishes the diving equipment from among the other kinds of the submersibles, for example: atmosphering diving suits (normobaric diving suits, one atmosphere diving suits - Photo 10), or manned underwater vehicles (Photo 11) that enable normobaric dives. Descent and ascend to water environment should be safety, therefore the diving equipment requires from the diver except operating skills, special health qualifications and training.

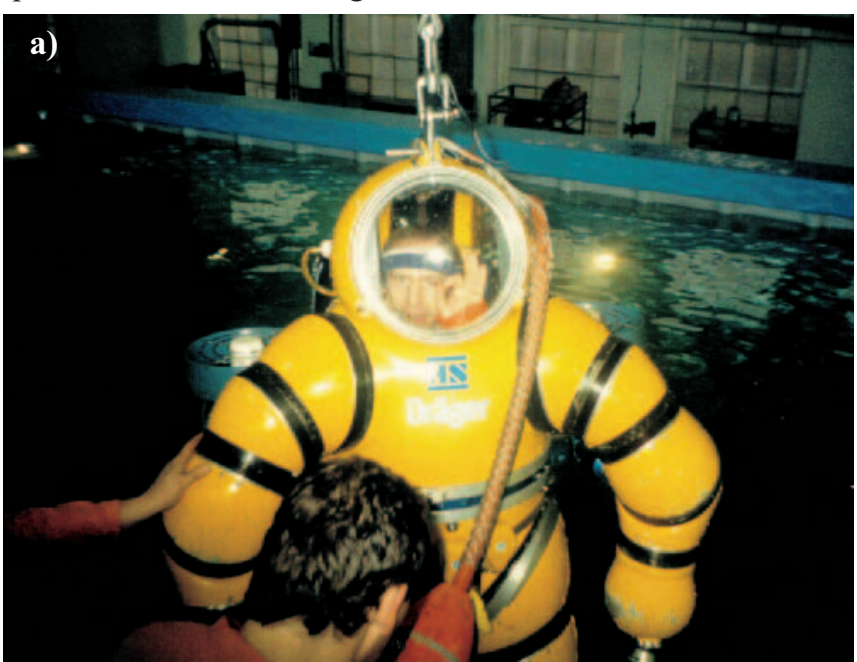

Photo 10. Armored suits: a) Newsuit (the own photography, courtesy Drägerwerk AG Germany)

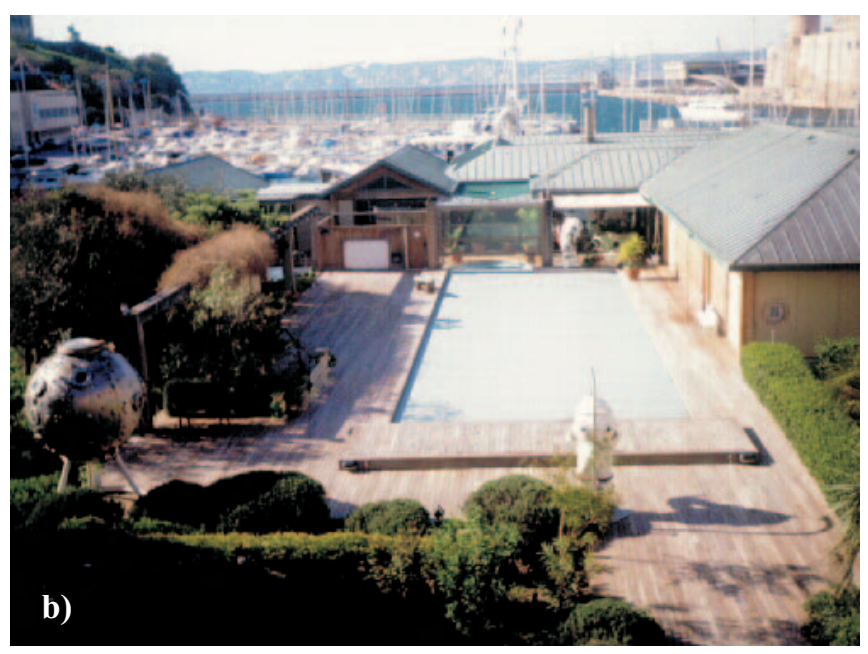

Photo 10. Armored suits: b) Russian armored suits in the villa of COMEX-President, Marsylia (the own photography, courtesy H. Delauze)
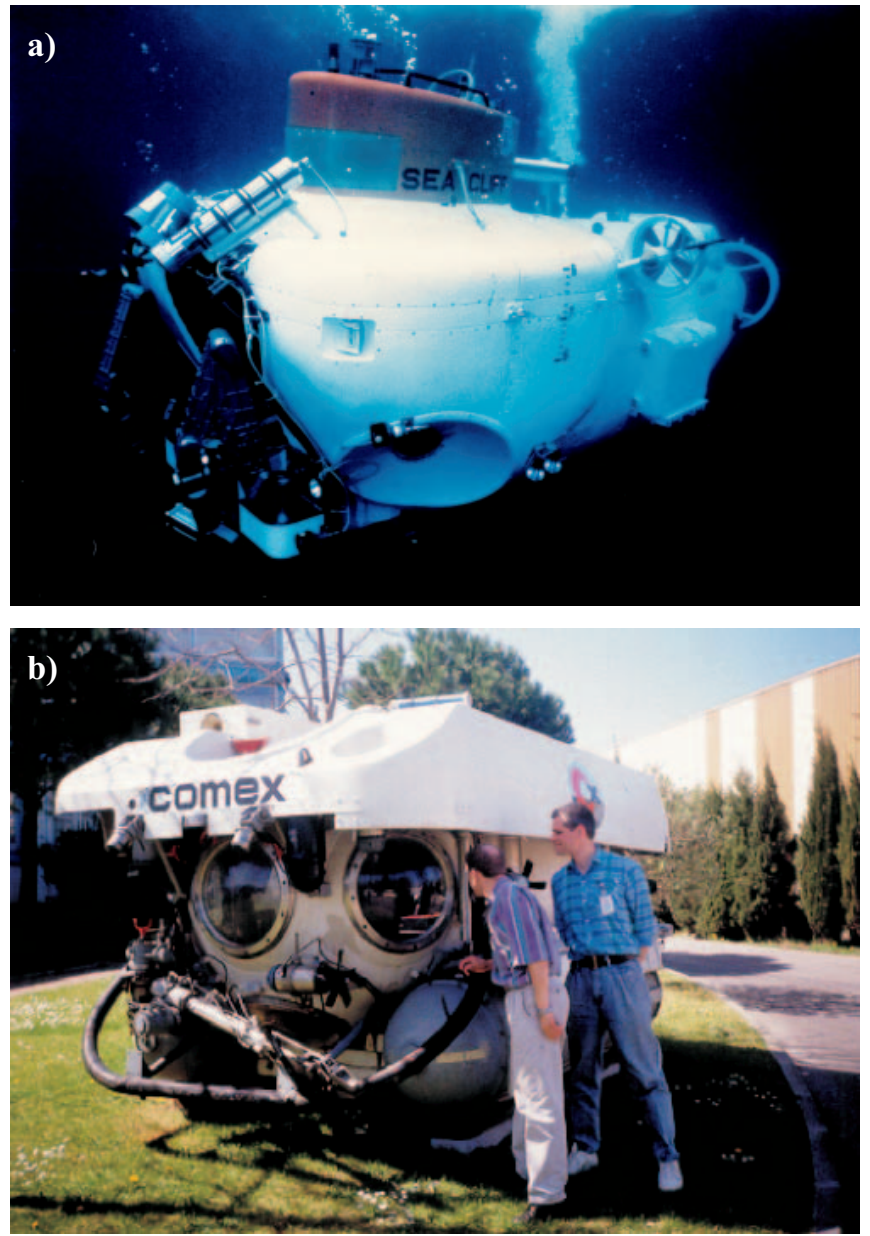

Photo 11. The underwater vessels - scientific vessels: a) the general view of the underwater vessel SeaCliff, b) the historical underwater vessel of Comex

\section{THE DIVING APPARATUSES AND THEIR CLASSIFICATION}

Except the traditional classification for the heavy and lightweight diving equipment there are many other classification criteria. Most divisions that have been presented in the literature are based on the diving apparatus constructional criteria [for example $[2,7,9]$. In this paper the new classification will be presented that seems to be more accurate and useful. Further, 

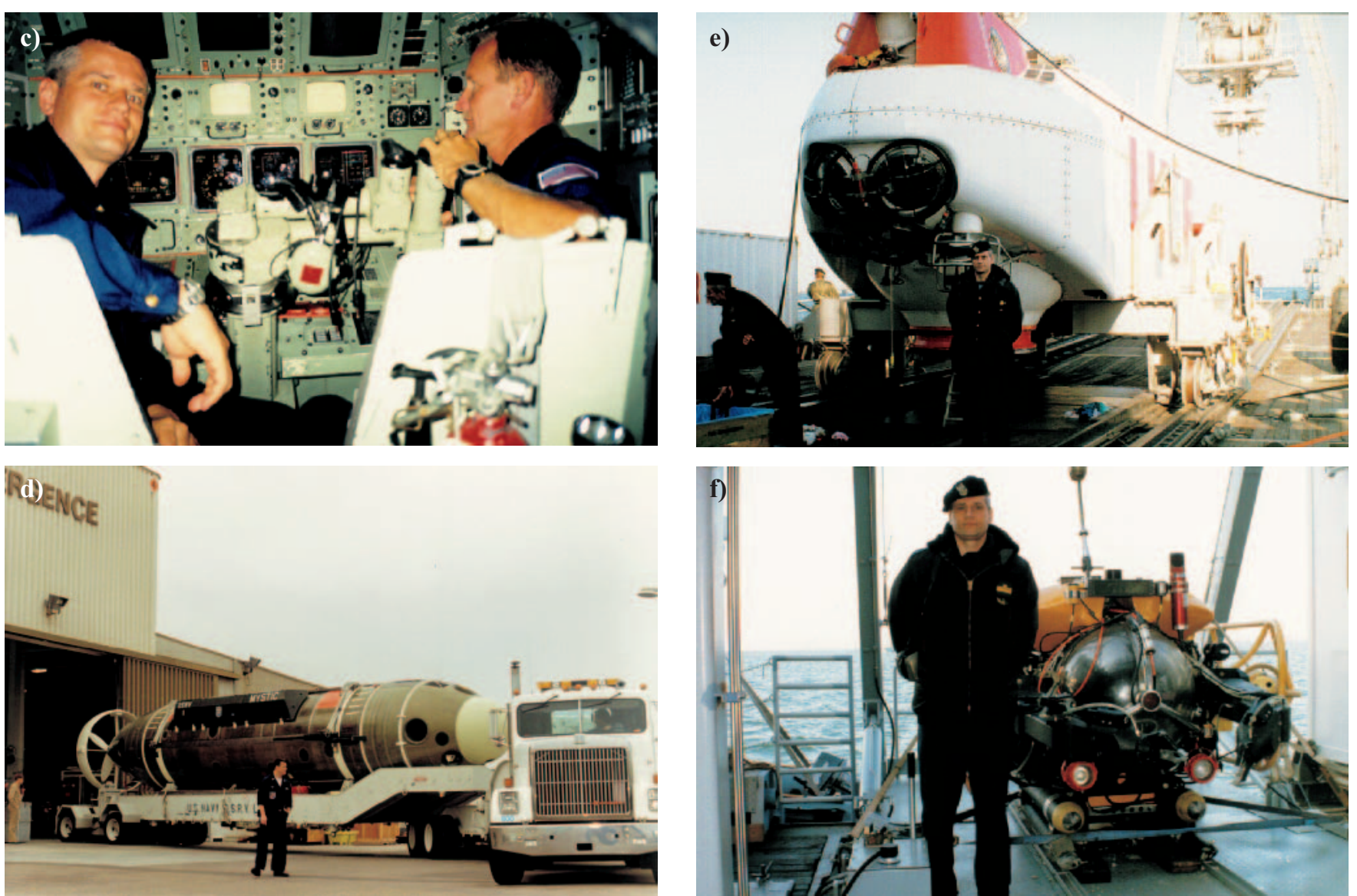

Photo 11. The underwater vessels - the rescue vessels: c) the view of DSRV Mystic cockpit (the own photography, courtesy Deep Submergence Unit San Diego), d) the general view of DSRV Mystic (the advertising photography, courtesy Deep Submergence Unit San Diego), e) the general view of the underwater vessel for rescue of the submersible crews (the own photography, courtesy HMS Belos Sweden), f) manned underwater robot produced in UK (the own photography, courtesy HMS Belos Sweden)

Table 3. Classification of the underwater diving apparatuses

\begin{tabular}{|c|c|c|c|c|c|c|c|c|c|c|c|}
\hline \multirow{2}{*}{\multicolumn{2}{|c|}{$\begin{array}{c}\text { Specification } \\
\begin{array}{c}\text { 1.breathing } \\
\text { species }\end{array}\end{array}$}} & \multicolumn{10}{|c|}{ Classification of the underwater diving apparatuses } \\
\hline & & \multicolumn{2}{|c|}{ air } & oxygen & \multicolumn{7}{|c|}{ mixed gases (most often: nitrox, helioks, trimix ,hydrox, hydreliox, neox) } \\
\hline \multicolumn{2}{|c|}{ 2.depth range } & \multicolumn{2}{|c|}{$0 \div 50 \mathrm{mH}_{2} \mathrm{O}$} & $\begin{array}{l}\text { up to } 6 \\
\mathrm{mH}_{2} \mathrm{O}\end{array}$ & \multicolumn{4}{|c|}{$0 \div 200 \mathrm{mH}_{2} \mathrm{O}$} & \multicolumn{3}{|c|}{ most often deeper than $200 \mathrm{mH}_{2} \mathrm{O}$} \\
\hline \multirow{3}{*}{ 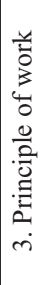 } & a) group & \multirow{2}{*}{\multicolumn{2}{|c|}{ of the open gas circuit }} & \multirow{2}{*}{$\begin{array}{l}\text { closed } \\
\text { gas } \\
\text { circuit }\end{array}$} & \multicolumn{4}{|c|}{ semi-closed gas circuit } & \multirow{2}{*}{\multicolumn{3}{|c|}{ closed gas circuit }} \\
\hline & $\begin{array}{l}\text { b) sub- } \\
\text { group }\end{array}$ & & & & \multicolumn{2}{|c|}{ premix } & \multicolumn{2}{|c|}{$\begin{array}{l}\text { preparing the } \\
\text { breathing gas during } \\
\text { diving process }\end{array}$} & & & \\
\hline & c)type & self-contained & hose supply & $\begin{array}{c}\text { self- } \\
\text { contained }\end{array}$ & $\begin{array}{c}\text { self- } \\
\text { contained }\end{array}$ & $\begin{array}{l}\text { hose } \\
\text { supply }\end{array}$ & $\begin{array}{c}\text { self- } \\
\text { contained }\end{array}$ & $\begin{array}{l}\text { hose } \\
\text { supply }\end{array}$ & $\begin{array}{c}\text { small } \\
\text { circulation }\end{array}$ & $\begin{array}{l}\text { increased } \\
\text { circulation }\end{array}$ & $\begin{array}{l}\text { high } \\
\text { circulation }\end{array}$ \\
\hline \multirow{3}{*}{ 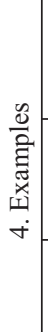 } & $\begin{array}{l}\text { Haux } \\
{[1968} \\
1982]\end{array}$ & PA-38/3600 & PL-70 & LAR V & - & FGG III & SM III & SM III-S & Elektrolung & - & GAK-600 \\
\hline & $\begin{array}{c}\text { Polish } \\
\text { constru- } \\
\text { ctions }\end{array}$ & PR-27 & UAN-82 & - & APW-6M & GAN-87 & APW-3 & - & - & - & - \\
\hline & $\begin{array}{l}\text { the other } \\
\text { examples }\end{array}$ & AGA MkII & KMB-10 & COBRA & ACSC & $\begin{array}{l}\text { Sealab III } \\
\text { (Fink Rig) }\end{array}$ & SIVA+ & - & Mk-15/16 & DOLPHIN 7 & CCBS \\
\hline \multicolumn{2}{|c|}{ 5. Remarks } & $\begin{array}{l}\text { not } \\
\text { recommended } \\
\text { to the } \\
\text { underwater } \\
\text { works }\end{array}$ & $\begin{array}{l}\text { recommended } \\
\text { to the } \\
\text { underwater } \\
\text { works at the } \\
\text { shallow and } \\
\text { mean depths }\end{array}$ & $\begin{array}{c}\text { military } \\
\text { diving }\end{array}$ & \multicolumn{4}{|c|}{$\begin{array}{l}\text { mostly used for the diving works performed } \\
\text { beyond the saturation zone (or the bail- } \\
\text { out apparatuses during saturation) and for } \\
\text { the operational diving at the large depths } \\
\text { (standard approximately } 150 \mathrm{~m} \mathrm{H}_{2} \mathrm{O} \text { ) }\end{array}$} & $\begin{array}{c}\text { military } \\
\text { diving at the } \\
\text { large depths }\end{array}$ & \multicolumn{2}{|c|}{$\begin{array}{l}\text { apparatuses used to underwater } \\
\text { works during saturation diving }\end{array}$} \\
\hline
\end{tabular}


we will deal with the diving apparatuses as the part of the diving equipment.

The diving apparatuses are defined as the part of the diving equipment that is responsible for supplying the diver the compressed breathing gas. The gas pressure is adequate to the diving depth. The breathing medium can be stored outside the apparatus and supplied by the suitable hose, the gasholders containing the breathing medium can be the integrate part of the diving apparatus or it can be obtained (or complemented) in chemical reaction.

To classify the diving apparatuses for the tasks assumed, the following criteria are the most convenient:

$\Rightarrow$ the kind of the breathing gas,

$\Rightarrow$ the operational depth range of the diving apparatus,

$\Rightarrow$ principle of operation.

The diving apparatus with chemical preparation or complementation of the breathing gas are not discussed here. Classification of the diving apparatuses according to the above criteria is presented in Table 3 . The presented here classification of the diving apparatuses used for underwater work enables gathering, systematising and analysing of those construction development trends.

Although the presented here classification is not excellent, it is the most complete classification that has been met in the professional literature. It has practically confirmed it usability at the diving apparatuses' data systemising and analysis.

\section{DISCUSSION AND CONCLUSIONS}

Development trends of the diving apparatuses and analysis of the development directions have shown in Europe and in the world the great interest in the semi - closed circuit diving apparatuses. It was several years before the great marked for these products has been opened (recreational diving use and beginning of the technical diving).

It was innovative in preparation of the diving apparatuses classification to use three criteria: the kind of the breathing gas, the operational depth range of the diving apparatus, and the principle of operation. The breathing gas used is the most important criterion. The other basic classification criteria follow from the first one; therefore it should be treated as the one criterion. Such approach to the problem has never been presented before, however it seems to be the most correct method of the diving apparatuses division.

\section{Acknowledgement}

This research was financially supported by the Polish Scientific Research Committee № 0 T00A 072 18: The mathematical models of UBA ventilation with partial regeneration of the breathing medium.

\section{BIBLIOGRAPHY}

1. Bachrach A.J., Desiderati B.M., Matzen M.M.: A pictorial history of diving. Best Publishing Co. 1988

2. Clarke D.W.: The history of breathing apparatus and current state of the art $\$ \mathrm{z}:+$ Lung and physiology and divers breathing apparatus. Proceedings from the International Workshop Ballater, Scotland, 1 $\div 4$ Nov. 1991: Department of Biomedical Sciences Marshal College Aberdeen 1992

3. Diving Manual: Ministry of Defence (Navy), B.R.2805 (Army Code No 61231) March 1982

4. Gussman J.: Człowiek zdobywa głębiny. Wydawnictwo Morskie Gdańsk 1984

5. Mer \& Océan - Spécial Cousteau 1997

6. Prace podwodne: Wydawnictwo Morskie Gdańsk 1971

7. Przylipiak M., Torbus J.: Sprzęt i prace nurkowe-poradnik. WMON Warszawa 1981

8. Rawlis J.: The history of commercial, military and sport diving. Trans. IMarE 101(1989) $161 \div 170$

9. The five methods for professional diving. Komunikat Drägerwerk AG Lübeck (Oct.1987)

10.The underwater handbook. Pr. zbiorowa pod red. C.W.Shilling, M.F.Werts, N.R.Schandelmeier: Plenum Press New York and London

11. US Navy diving manual. Best Publishing Co. Carson California 1980

12.US Navy diving manual (revision 3). The Direction of Commander, Naval Sea Systems Command 1993

\section{CONTACT WITH THE AUTHOR}

Ryszard Kłos, D. Sc., Eng.

Department of Diving Technology

and Underwater Activities

Polish Naval Academy

Śmidowicza 69

81-103 Gdynia POLAND

e-mail:skrzyn@wp.pl

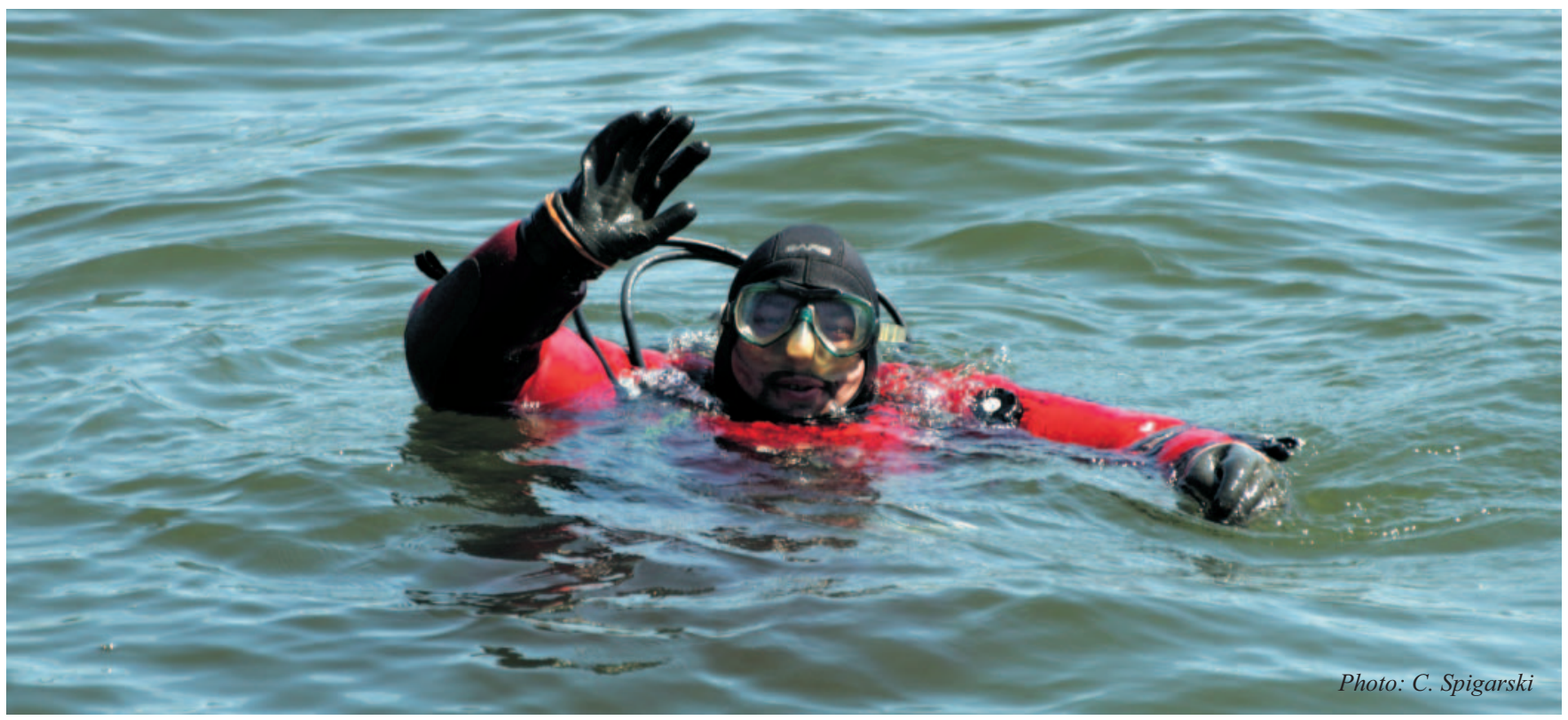




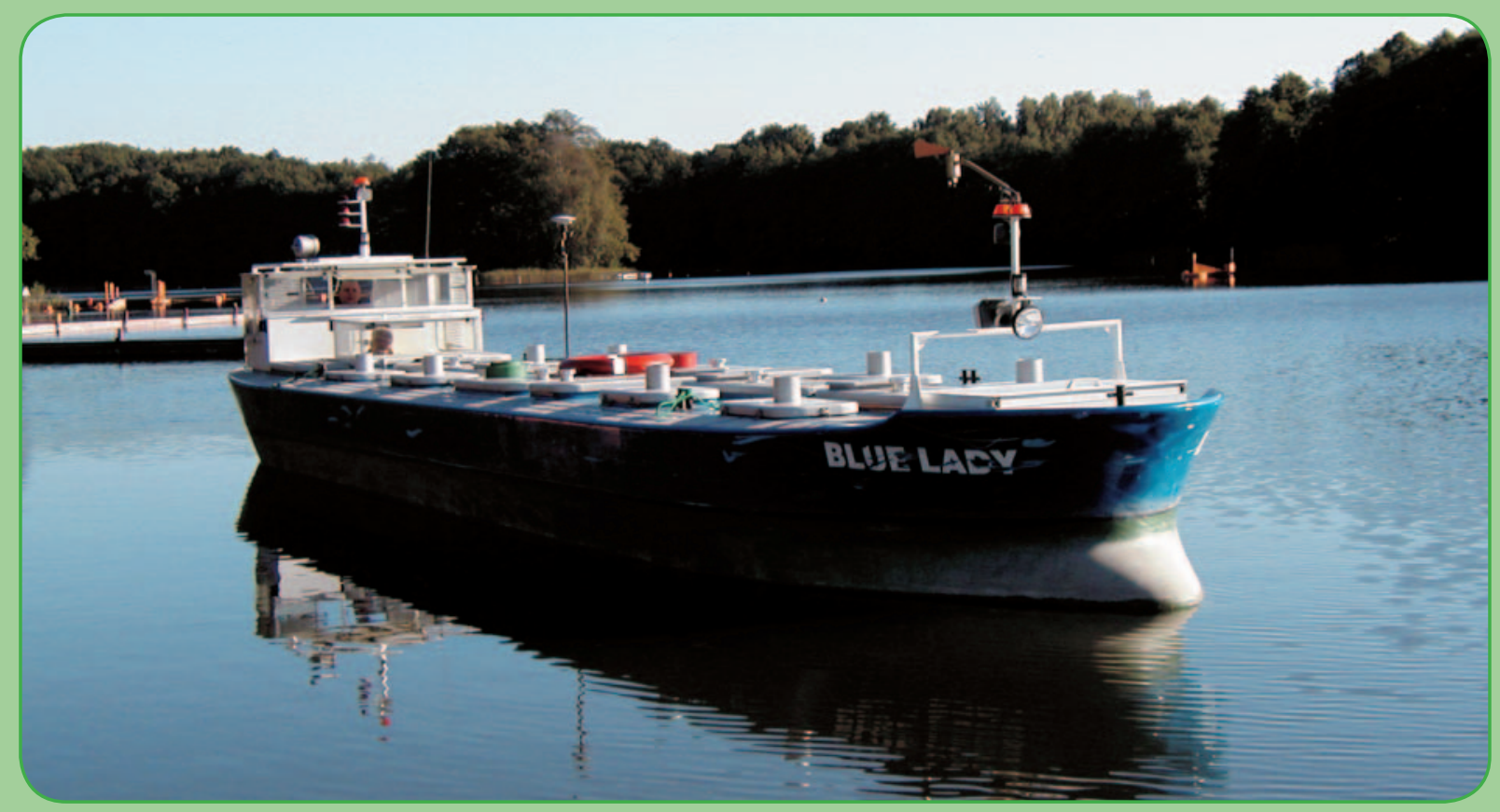

The Ship Handling Research and Training Centre at Ilawa is owned by the Foundation for Safety of Navigation and Environment Protection, which is a joint venture between the Gdynia Maritime University, the Gdansk University of Technology and the City of Ilawa.

\section{Two main fields of activity of the Foundation are:}

- Training on ship handling. Since 1980 more than 2500 ship masters and pilots from 35 countries were trained at Iława Centre. The Foundation for Safety of Navigation and Environment Protection, being non-profit organisation is reinvesting all spare funds in new facilities and each year to the existing facilities new models and new training areas were added. Existing training models each year are also modernised, that's why at present the Centre represents a modern facility perfectly capable to perform training on ship handling of shipmasters, pilots and tug masters.

- Research on ship's manoeuvrability. Many experimental and theoretical research programmes covering different problems of manoeuvrability (including human effect, harbour and waterway design) are successfully realised at the Centre.

The Foundation possesses ISO 9001 quality certificate.

\section{Why training on ship handling?}

The safe handling of ships depends on many factors - on ship's manoeuvring characteristics, human factor (operator experience and skill, his behaviour in stressed situation, etc.), actual environmental conditions, and degree of water area restriction.

Results of analysis of CRG (collisions, rammings and groundings) casualties show that in one third of all the human error is involved, and the same amount of CRG casualties is attributed to the poor controllability of ships. Training on ship handling is largely recommended by IMO as one of the most effective method for improving the safety at sea. The goal of the above training is to gain theoretical and practical knowledge on ship handling in a wide number of different situations met in practice at sea.

For further information please contact:

The Foundation for Safety of Navigation and Environment Protection

Head office:

36, Chrzanowskiego street

80-278 GDAŃSK, POLAND

tel./fax: $+48(0) 583415919$
Ship Handling Centre: 14-200 IŁAWA-KAMIONKA, POLAND tel./fax: +48 (0) 896487490 e-mail: office@ilawashiphandling.com.pl e-mail: office@portilawa.com 